Egyptian

Orthodontic Journal

\title{
DIGITAL EVALUATION OF CHANGES IN OCCLUSION DUE TO ORAL APPLIANCE THERAPY IN OBSTRUCTIVE SLEEP APNEA
}

\author{
Hany Salah El- Din Eid ${ }^{1}$, Hatem S. Saif El-Din ${ }^{2}$
}

\section{ABSTRACT}

Objectives: The present study was designed to investigate the changes in occlusion caused by dental side effects of oral appliance therapy in obstructive sleep apnea syndrome compared with continuous positive airway pressure (CPAP) therapy. Methods: Twenty cases $(n=20)$ over 20 years of age and diagnosed with obstructive sleep apnea syndrome (OSAS) (apnea-hypopnea index AHI >5) based on polysomnography were selected and randomized for either Mandibular advancement splint (MAS) (n10) or a tongue stabilizing device (TSD) (n10) therapy. Tested and compared dental side effects in 6oth groups of patients treated with oral appliances versus control group (n10) composed of OSAS patients elected to be treated with continuous positive airway pressure (CPAP). From all patients, dental impressions were obtained and digitally scanned at baseline and after 6 months of treatment to digitally determine variables related to dental changes and occlusion.

Mean and standard deviation were used for summarizing data. Student's $t$ test was used for testing significant results between two sample means; paired $t$ test was used for testing significant results between mean values for the same individuals before and after intervention. Significant results were considered if $p<0.05$, high significant results were considered if $p<0.01$. Results: Oral appliance therapy showed small but significant dental changes compared with СРАР. In the MAS group, overbite and overjet decreased $1.2( \pm 1.1) \mathrm{mm}$

1- Associate professor of Orthodontics, Faculty of Dentistry, Miser University for Science and Technology, 6th of October city, Egypt.

2- Lecturer of Orthodontics, Faculty of Dentistry, Ain Shams University, Cairo, Egypt. 
Egyptian

Orthodontic Journal

and $1.5( \pm 1.5) \mathrm{mm}$, respectively. Furthermore, we found a significantly Carger antero-posterior change in the occlusion $(-1.3 \pm 1.5 \mathrm{~mm})$ compared to the CPAP group $(-0.1 \pm 0.6 \mathrm{~mm})$. In addition, in all groups, a significant decrease in number of occlusal contact points in the premolar region was found. Conclusion: we found that using an oral appliance therapy and CPAP for 6 months may result in dental changes in OSAS patients, particularly an MAS appliance, where a TSD appliance showed less impact on occlusion.

\section{INTRODUCTION}

Obstructive sleep apnea (OSA) is known as a complex multifactorial condition that occurs by multiple anatomic and physiological factors ${ }^{[1]}$. It is characterized by repetitive total or partial obstruction of the upper airway during sleep resulting in sleep fragmentation and oxygen desaturation $^{[2,3]}$. Risk factors include male gender and obesity ${ }^{[4]}$, ethnicity $^{[5]}$ and certain types of craniofacial structures ${ }^{[6]}$ have been recognized as increasing susceptibility to this disease. Morbidity and mortality can also be recognized in OSA patients and has a significant direct relation to cardiovascular ${ }^{[7,8]}$ and cerebrovascular diseases ${ }^{[9,10]}$, excessive daytime drowsiness ${ }^{[11]}$, and prone failure during operating heavy machinery or daytime routine motorized traffic maneuvering ${ }^{[12-14]}$, and not uncommon to be accompanied by loud audible snoring that can lead to family problems due to chronic discomfort of an individual sharing the same dormitory. More OSAS symptoms include; (sexual) incompetence, neurocognitive deficits, and higher rates of cardiovascular and cerebrovascular morbidity and mortality ${ }^{[2-5]}$. The apnea-hypopnea index (AHI) usually expresses the severity of the problem, i.e., the mean number of apneas and hypopneas per hour of sleep and further classified as mild (AHI 5-15), moderate (AHI 15-30), or severe (AHI $>30)^{[6]}$. The prevalence of OSA varies depending on diagnostic criteria and population studied $^{[15]}$. Other investigations also concluded that among adults aged 30-69 years, 17\% of adults suffered mild or worse sleep disordered breathing (AHI $\geq 5$ ), and $5.7 \%$ of adults had moderate or worse sleep disordered breathing ${ }^{[16]}$. As such, OSA is recognized as a significant public health issue $e^{[12-14]}$. 
Egyptian

Orthodontic Journal

The most common protocols for handling the condition include but not limited to; conservative non-invasive regimes such as weight loss and nasal continuous positive airway pressure $(\mathrm{CPAP})^{[17]}$. However, increased frequency of lack of patient's compliance and difficulties with CPAP has raised the interest in oral devices as an alternative. Among the most common intraoral devices that has the potential of increasing the air flow through the upper airway structure by the action of protruding the mandible during sleep. Several investigations have addressed the effectiveness of such devices and suggested a variety of designs that have shown to be effective in a significant number of patients, particularly those with mild to moderate $\mathrm{OSA}^{[18-21]}$. In cases of mild to moderate OSA; it is recommended by the American Academy of Sleep Medicine practice parameters, to use MAS instead of CPAP due to intolerability to such treatment or upon patient's desire ${ }^{[22]}$. Meanwhile, tongue stabilizing device (TSD) is a preformed appliance and uses suction to protrude the tongue and improve upper airway structure and function. The earlier designs were similar to an oral screen, covering the upper and lower teeth to assist retention, with a flexible bulb into which the tongue was protruded $^{[23]}$. The current design has no dental coverage, reduced bulk, and has the bulb being retained in place only by suction. There are currently only limited data on the efficacy of the current device, which is commercially available ${ }^{[24]}$. As they are not reliant on the teeth for retention, TSD have been proposed as an option for patients with a reduced number or absence of teeth (hypodontia, edentulism), or compromised dental health (periodontal disease), However, a patient with full set of upper and lower teeth does not contraindicate the use of TSD.

Oral appliance therapy is has been proven to be a reliable alternative in the treatment of OSAS, particularly in cases of mild to moderate and in patients refusing or have difficulties tolerating $\mathrm{CPAP}^{[25]}$. Oral appliances aid the upper airway to widen up during sleep by the way of keeping the mandible in a forward and downward position [26]. However, some mild and "transient" side effects was reported at the beginning period of oral appliance use and include but not limited to; tooth ache, temporomandibular joint pain, myofacial tenderness, dry mouth, excessive salivation, and gum inflammation ${ }^{[27-35]}$.

The action of mandibular and tongue protrusions necessary for enhancing the function of upper airway, is eventually accompanied by 
Egyptian

Orthodontic Journal

abnormal pressure of small but chronic magnitude on the teeth, has resulted in other forms of dental side effects manifested as undesirable teeth movements.

In previous investigations, dental side effects attributed to long-term use of an oral appliance have been studied with dental cast analysis ${ }^{[33,36-39]}$. However, most of these studies were retrospective, included inadequate study samples, lacking the inclusion of a control group or only limited to mild or moderate OSAS patients that used only (MAS) devices ignoring the (TSD) appliance users as regarding dental effects. Therefore, the comparison between the two devices regarding the extent of dental side effects needs further study. The objectives of this study were to assess:

1- The incidence of dental side effects following utilization of oral appliance therapy in adult patients with mild-to-severe OSAS.

2- Comparison between two market competing oral appliances (MAD) and (TSD) regarding occurrence and severity of dental side effects.

\section{MATERIALS AND METHODS}

\section{Patient selection}

In a previous research study, the efficiency of oral appliance therapy in OSAS, compared with CPAP, has been identified [40]. All patients in this study were selected from the Department of Chest Medicine, branch of sleep disorders and mechanical Ventilation at Misr University for Science and Technology, Medical Hospital, Egypt. Subjects diagnosed with OSAS (AHI >5) based on polysomnography and were above 20 years of age [41] were chosen. If patients matched specific medical, psychological, and dental inclusion criteria, they were fit for the study, And after signing a consent form they were consequently randomized for either (MAS) (n10) or (TSD) (n10) therapy.

For the present study, we tested and compared dental side effects in both groups of patients treated with oral appliances versus control group (n10) composed of OSAS patients elected to be treated with CPAP. Patients considered unsuccessful were given the option of being treated using alternative therapy at any time during the follow-up and excluded from the study. Furthermore, patients were excluded if oral appliance was used $<5$ nights a week or $<6 \mathrm{~h}$ per night during follow-up. 
Egyptian

Orthodontic Journal

\section{Study design}

From all patients, dental impressions were obtained and digitally scanned at baseline and after 6 months of treatment to digitally determine variables related to dental changes and occlusion.

\section{Impression}

The impression was obtained with a high quality alginate material, e.g. Cavex (Cavex Holland bv., Haarlem, Holland).

\section{Digital scanning and recording of data:}

Using the (ScanIt OrthoImpression program), for alginate or silicone impression scanning (3Shape Ortho System ${ }^{\mathrm{TM}}$ ). Prepared maxillary impression for scanning has been placed in the dedicated fixture, potential excess moisture has been wiped with a tissue and inserted into the scanner with incisors facing the scanner door. Scanning has been proceeded with front teeth facing the scanner. Model impression fixture removed from scanner after conclusion of the procedure.

Previous steps were repeated for mandibular impression. The excess material from the scanned impressions was cut using a control points to define cut area. A previously prepared wax bite taken in centric occlusion was inserted into the scanner with mandibular side facing the scanner door; the scan has been aligned to the wax bite by placing pairs of points on the common areas between bite and scanned impressions to digitally mount virtual casts in centric occlusion. Finally a base model from the list for the maxillary and mandibular base model list has been selected (ABO max and $\mathrm{ABO}$ mand).

Once the virtual cast had been listed and categorized according to the designated study group, it has been fed to a digital orthodontic analyzer (3Shape Ortho Analyzer ${ }^{\mathrm{TM}}$ ) to automatically identify each tooth's axis and rotation center. Tools include overjet, overbite and occlusion maps. The previous steps has been repeated after 6 months for every patient to digitally compare before and after changes in over jet and overbite, as well as the difference (baseline versus follow-up) in anteroposterior relationship digitally measured at the buccal sides of the first molars. A mark was placed on the buccal side of the maxillary molar representing the buccal groove of the mandibular first molar. If negative values were observed then a mesial shift of the dentition in the mandible is identified 
Egyptian

Orthodontic Journal

and positive values indicate a distal shift. In case the first permanent molars were missing the second permanent molars were used for measurements. Anterior overjet was defined as the horizontal distance from the mesial end of the incisal edge of the upper central incisor to the labial plane of the lower central incisor. Anterior overbite was defined as the vertical distance of the incisal edge of the lower central incisor to the horizontal projection of the incisal edge of the upper central incisor on the labial plane of the lower central incisor. In addition, occlusal contact points (maximum intercuspation between maxillary and mandibular teeth in centric occlusion) were recorded on the digital models. The total count of occlusal contact points was determined for the premolar region and for the cuspid-incisor region of the digital upper and lower models. Patients having posterior fixed bridges were included in all studies (max. 3 units). Patients possessing edentulous areas more than one tooth per quadrant, anterior bridge work or implants, were also excluded from the study as well as patients diagnosed as bruxism or having moderate to severe periodontal problem.

The (MAS) appliance used in this study (Vital Sleep®, USA) consisted of two splints, forcing the patient's mandible to be positioned in a forward and downward position (Figure 1). This type of oral appliance is often referred to as a mandibular adjusting splint appliance. When patients instructed to begin oral appliance therapy, the mandible was set at half of the patient's maximum protrusion. By turning a positioning hex key that was located anteriorly in the appliance; patients were able to adjust and control the mandibular protrusive position at $0.2 \mathrm{~mm}$ increments with each turn. After being accommodated to such protrusive position during approximately 14 days period, the patients were instructed to further adjust the oral appliance during another 2-week period. If OSAS symptoms. If such prescribed amount of protrusion of the mandible resulted in discomfort or pain while symptoms still persists, then the patient is excluded from the study and investigated for TMJ internal disorder. It was important to keep the vertical dimension of the oral appliance constant during the entire follow up period. The tongue stabilizing device used in this trial was a preformed non-adjustable silicon appliance (Good Mourning, Snore Solution, USA) (Figure 2). Patients were instructed to rinse the device with water, place the flanges of the TSD on the outside of the upper and lower lips and insert the tongue into the bulb as far as possible, then squeeze the bulb to generate 
suction. Patients were advised to increase the suction by protruding the tongue further and/ or squeezing the bulb more in case the appliance become loose or be insufficiently retentive.

Mean and standard deviation was used for summarizing data. Student's $t$ test was used for testing significant results between two sample means; paired t test was used for testing significant results between mean values for the same individuals before and after intervention. Significant results is considered if $p<0.05$, high significant results was considered if $\mathrm{p}<0.01$.

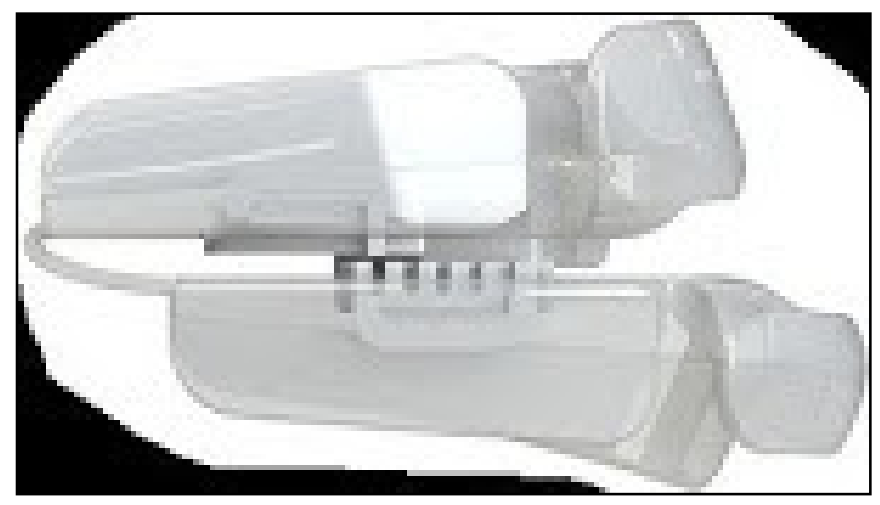

Figure 1: Photograph of upper and lower plates of the mandibular advancement splint.

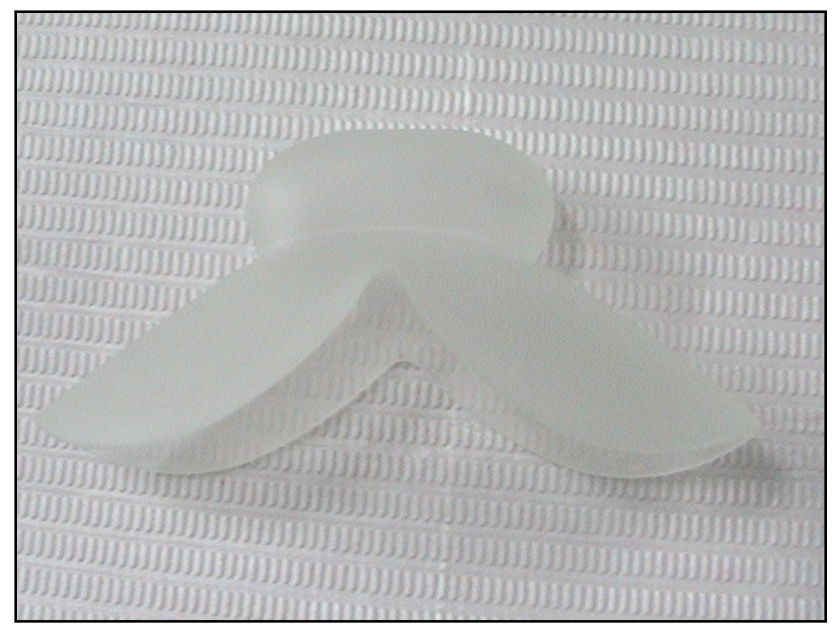

Figure 2: Photograph of the tongue stabilizing device. 
Egyptian

Orthodontic Journal

\section{RESULTS}

For analysis, 31 patients were included in the study, the (MAS) group $(n=10)$, the (TSD) $(n=10)$ group and the control group (CPAP) $(\mathrm{n}=11)$ respectively. The mean follow-up period was $6.3( \pm 0.2)$ months in all groups. No significant difference was found between oral appliance groups regarding number of nights or hours per night of therapeutic usage of both appliances (Table 1).

Digital study cast analysis:

No significant differences were found between the oral appliances groups and CPAP group regarding baseline characteristics of the patients included in the analysis, (Table 2). A significant decrease in overbite $(-1.2 \pm 1.1 \mathrm{~mm} ; \mathrm{p}<0.00)$ and overjet $(-1.5 \pm 1.5 \mathrm{~mm} ; \mathrm{p}<0.00)$ was found in the (MAS) appliance group compared to the CPAP group as well as a significantly $(\mathrm{p}<0.00)$ larger antero-posterior change in occlusion $(-1.3 \pm 1.5)$ compared to the CPAP group $(-0.1 \pm 0.6 \mathrm{~mm})$. On the other hand, the (TSD) group statistics did not reveal any significant changes from control group regarding the above variables (Table 2). There was no signs of an openbite tendency between the upper and lower dental arch in the cuspid-incisor region upon evaluation of the number of occlusal contact points in either the oral appliances groups or the CPAP group. However, in the premolar region in both the oral appliances groups and CPAP group, a significant decrease in the number of occlusal contact points $(\mathrm{p}<0.00)$ and $(\mathrm{p} 00.03)$ respectively (Table 2$)$. Also a significantly $(\mathrm{p}<0.00)$ larger antero-posterior change in occlusion $(-1.3 \pm 1.5$ for MAS, $-1.4 \pm 1.4$ for TSD) was found in both appliances groups compared to the CPAP group $(-0.1 \pm 0.6 \mathrm{~mm})$ (Table 2$)$. 
Table 1: Age, therapeutic use, and number of teeth for patients who completed the 6 months follow-up.

\begin{tabular}{|c|c|c|c|c|}
\hline Variable & $(\mathbf{M A S})(\mathbf{n 1 0}) \mathbf{a}$ & (TSD) (n10)a & CPAP (11)a & $\begin{array}{r}\text { Difference } \\
\text { (p value)b }\end{array}$ \\
\hline Age (years) & $35.7 \pm 8.9$ & $37.6 \pm 10.1$ & $38.9 \pm 8.1$ & NS \\
\hline \multicolumn{5}{|c|}{ Therapeutic use } \\
\hline Nights/ week & $6.9 \pm 0.4$ & $6.7 \pm 1.1$ & $6.8 \pm 1.1$ & NS \\
\hline Hours/ night & $7.1 \pm 0.8$ & $6.7 \pm 1.3$ & $6.9 \pm 1.3$ & NS \\
\hline \multicolumn{5}{|c|}{ Number of teeth } \\
\hline Upper arch & $12.7 \pm 1.5$ & $13.1 \pm 1.8$ & $12.1 \pm 1.9$ & NS \\
\hline Lower arch & $13.1 \pm 1.4$ & $13.0 \pm 1.5$ & $13.0 \pm 1.3$ & NS \\
\hline
\end{tabular}

CPAP continuous positive airway pressure, NS not significant, a values are means \pm standard deviations, $b$ paired t test.

Table 2: Digital cast analysis characteristics at baseline and 6 months follow-up.

\begin{tabular}{lllll}
\hline Variable & (MAS) $($ n10)a & (TSD) $($ n10)a & CPAP (11)a & Difference (p value)b
\end{tabular}

Occlusal contact points cuspid-incisor region (no.)

$\begin{array}{lllll}\text { Baseline } & 2.5 \pm 1.7 & 2.6 \pm 1.5 & 3.2 \pm 2.0 & \text { NS } \\ \text { Follow-up } & 2.2 \pm 1.8 & 2.3 \pm 1.7 & 3.0 \pm 1.9 & \text { NS }\end{array}$

Difference

(p value)b NS NS NS

Occlusal contact points (pre)molar region (no.)

$\begin{array}{lllll}\text { Baseline } & 6.8 \pm 2.6 & 6.9 \pm 2.7 & 6.9 \pm 2.6 & \text { NS } \\ \text { Follow-up } & 5.1 \pm 2.3 & 6.3 \pm 2.4 & 6.4 \pm 2.3 & \text { NS }\end{array}$

$\begin{array}{lllll}\text { Follow-up } & 5.1 \pm 2.3 & 6.3 \pm 2.4 & 6.4 \pm 2.3 & \text { NS }\end{array}$

$\begin{array}{lll}\text { Difference } & \\ \mathrm{p} \text { value }) & \mathrm{p}<0.00 \quad \mathrm{p}<0.00 \quad \mathrm{p} 00.03\end{array}$

Delta overbite $(\mathrm{mm})$

$$
\begin{array}{cccc}
-1.2 \pm 1.1 & -0.1 \pm 0.6 & \mathrm{p}<0.00 \\
& -0.2 \pm 0.5 & -0.1 \pm 0.6 & \mathrm{NS}
\end{array}
$$

Delta overjet (mm)

$$
\begin{array}{cccc}
-1.5 \pm 1.5 & -0.2 \pm 0.7 & \mathrm{p}<0.00 \\
& -0.2 \pm 0.6 & -0.2 \pm 0.7 & \mathrm{NS}
\end{array}
$$

Antero-posterior movement ( $\mathrm{mm})$

$$
\begin{array}{cccc}
-1.3 \pm 1.5 & -0.1 \pm 0.6 & \mathrm{p}<0.00 \\
& -0.1 \pm 0.5 & -0.1 \pm 0.6 & \mathrm{NS}
\end{array}
$$

$\overline{\text { CPAP continuous positive airway pressure, NS not significant, a values are means } \pm}$ standard deviations, b paired $t$ test. 
Egyptian

Orthodontic Journal

\section{DISCUSSION}

As far as our knowledge, this study is the first study where changes in dental occlusion as a result of utilization of two types of oral appliance therapy were evaluated along with a controlled control group concerning mild-to-severe OSAS patients. In most instances, oral appliance therapy is considered a treatment option that lasts for life. This study showed that values of overjet, overbite and number of occlusal contact points are reduced and a different antero- posterior relationship, are among dental changes most likely to occur. In addition, we found a direct relation between the decrease in overbite and overjet accompanying of mandibular protrusion associated with wearing an (MAS) appliance.

In the (MAS) group, that patients would had a shift in occlusion from class I to class III molar and cuspid relationship or a shift from class II to class I or III compared to (TSD) and CPAP groups.

Changes in overbite, overjet, and antero-posterior relationship of the static occlusion as a consequence of enduring utilization of oral appliance therapy have also been described in previous studies ${ }^{[33,35,36,38,42]}$, however those studies did not compare their results to another type of oral appliances. These changes can be occurring as a result of facially directed force applied on the mandibular incisors and a palatally directed force applied to the maxillary incisors in conjunction with (MAS) appliance therapy while the mandible is being pulled backward to return to a more distal position. Meanwhile, in the (TSD) group, the mode of action of the appliance depends on clearing the airway by means of tongue protrusion, therefore, minimizing the need for mandibular protrusion along with maintaining as much as possible the chondylar rest position anteroposteriorly. Thus, creating a more comfortable muscular balance, that contributed to the stability in antero-posterior occlusal relations. Ringqvist and co-workers ${ }^{[29]}$ found no significant changes in overjet and overbite after 2 years of oral appliance therapy. This may be attributed to the differences in appliance design. The (MAS) oral appliance used in our study covered the entire upper and lower dental arch facially and lingually, meanwhile, the appliance that was used by Ringqvist and co-workers, had both frontal areas not covered, therefore, less forces applied to the upper and lower incisors were expected. This coincides 
with the absence of significant changes in overjet and overbite. In another study by Ghazal and coworkers, they found significant decrease in overbite but not overjet using a Thornton Adjustable mandibular Positioner similar to the one used in the present study ${ }^{[43]}$. However, in those particular studies, only patients with mild and moderate OSAS were investigated $^{[29,43]}$. While in this present study, patients with mild, moderate, and severe OSAS were included. The relationship between the efficacy of an oral appliance and the amount of mandibular protrusion has been addressed in past studies ${ }^{[44,}{ }^{45]}$. Therefore, adding another explanation regarding the different findings of changes of the overjet and overbite, where cases of mild to moderate OSAS patients, less protrusion is expected, therefore, less severe dental side effects. Those observations have been verified in our study due to the results obtained in the (TSD) group. Both separate findings regarding (MAS and TSD) dictates the importance of directing and advising patients who are treated with an oral adjusting appliance, about the risks of advancing the mandible beyond the optimal comfortable protrusive position on one hand, and dental changes that are expected to occur more with (MAS) group of appliances on another hand.

Several other studies ${ }^{[33,38,39]}$, found a significant decrease in the number of occlusal contact points in the premolar region in both the oral appliance groups and the CPAP group and that was the case scenario regarding the present study. After 2 years of oral appliance use, MartinezGomis and co-workers ${ }^{[46]}$ also found a significant reduction in posterior occlusal contact points. This tendency, however, seems to corrects itself after a period of 2-5 years of treatment. The reason for this correction can be attributed to the production of a new occlusal equilibrium over time. Therefore, it seems logic that such dental changes tend to adapt in favor of functional occlussal scheme. In this study, we also found a decrease in the number of occlusal contact points in the CPAP group. One study supported the hypothesis that nasal CPAP may change craniofacial form and may alter the relationship between the dental arches ${ }^{[47]}$, where a palatal inclination of the maxillary incisors after long-term nasal CPAP. This can be explained as nasal CPAP is administered through a tight mask, and it could be hypothesized that the pressure of this mask results in retroclining forces on the anterior part of the upper dental arch. 
Egyptian

Orthodontic Journal

Ueda and co-workers ${ }^{[48]}$, suggested certain jaw exercises in patients using an oral appliance, aiding to alleviate tension of the muscles of mastication and aid the repositioning of the mandible to the comfortable centric relation after several nights of appliance use. In addition these exercises may minimize the occlusal functional changes in susceptible patients specially those using an oral appliance like (MAS) that are prone to occlusal changes.

In conclusion, we found that using an oral appliance therapy and CPAP for 6 months may result in dental changes in OSAS patients. However, when addressing a serious disorder as OSAS, life saving of the patient should be of priority than the maintenance of a patients' normal occlusal relationship, in a minor form where function is still preserved. Deciding to stop treatment using oral appliance therapy due to alterations in dento-occlusal relationship should only be considered in individuals who are able to tolerate or accept another efficient treatment alternative for OSAS.

Finally, more studies should be made testing more varieties of oral appliance used for the same purpose over a longer duration of use by OSAS patients.

\section{REFERENCES}

1. Cistulli P, Sullivan C, eds. Pathophysiology of sleep apnea. In: Sleep and breathing. New York: Marcel Dekker Inc, 1994.

2. Anonymous. Sleep-related breathing disorders in adults: recommendations for syndrome definition and measurement in clinical research. Sleep 1999;22:667-89.

3. Qureshi A, Ballard RD. Obstructive sleep apnea. J Allergy Immunol 2003;112:643 51 .

4. Redline S. Epidemiology of sleep-disordered breathing. Semin Respir Crit Care Med 1998;19:113-22.

5. Ancoli-Israeli S, Kripke D, Klauber M, Mason W, Fell R, Kaplan O. Sleep-disordered breathing in community-dwelling elderly. Sleep 1991;14:486-95. 
6. Battagel J, L'Estrange P. The cephalometric morphology of patients with obstructive sleep apnoea. Eur J Orthod 1996;18:557-69.

7. Guilleminault C, Tilkian A, Dement WC. The sleep apnea syndromes. Annu Rev Med 1976;27:465-84.

8. Young T, Peppard P, Palta M, et al. Population based study of sleep-disordered breathing as a risk factor for hypertension. Arch Intern Med 1997;157:1746-52.

9. Spriggs DA, French JM, Murdy JM, Bates D, James OF. Historical risk factors for stroke: a case control study. Age Aging 1990;19:280-7.

10. Palomaki H. Snoring and the risk of ischaemic brain infarction. Stroke 1991;22:1021-25.

11. Guilleminault C, Partinen M, Quera-Salva MA, Hayes B, Dement WC, Nino-Murcia G. Determinants of daytime sleepiness in obstructive sleep apnea. Chest 1988;94:32-7

12. Aldrich M. Automobile accidents in patients with sleep disorders. Sleep 1989;6:487-94.

13. Liam CK, How LG, Tan CT. Road traffic accidents in patients with obstructive sleep apnoea. Med J Malaysia 1996;51:143-5.

14. George CF. Reduction in motor vehicle collisions following treatment of sleep apnoea with nasal CPAP. Thorax 2001;56:508-12.

15. Young T, Palta M, Dempsey J, Skatrud J, Weber S, Badra S. The occurrence of sleep-disordered breathing among middle-aged adults. New Engl J Med 1993;328:1230-5.

16. Young T, Peppard PE, Taheri S. Excess weight and sleep-disordered breathing. J Appl Physiol 2005;99:1592-9.

17. Sullivan CE, Issa FG, Berthon-Jones M, Eves L. Reversal of obstructive sleep apnoea the continuous positive airway pressure applied through the nares. Lancet 1981;18:862-5.

18. Mehta A, Qian J, Petocz P, Darendeliler MA, Cistulli PA. A randomized controlled study of a mandibular advancement splint for obstructive sleep apnoea. Am J Respir Crit Care Med 2001;163:1457-61. 
19. Pitsis AJ, Darendeliler MA, Gotsopolous H, Petocz P, Cistulli PA. Effect of vertical dimension on efficacy of oral appliance therapy in obstructive sleep apnea. Am J Respir Crit Care Med 2002;166:860-64.

20. Gotsopolous H, Chen C, Qian J, Cistulli PA. Oral appliance therapy improves symptoms in obstructive sleep apnea: a randomized, controlled trial. Am J Respir Crit Care Med 2002;166:743-8.

21. Ng AT, Gotsopolous H, Qian J, Cistulli PA. Effect of oral appliance therapy on upper airway collapsibility in obstructive sleep apnea. Am J Respir Crit Care Med 2003;168:238-41.

22. Kushida CA, Morgenthaler TI, Littner MR, et al. Practice parameters for the treatment of snoring and obstructive sleep apnea with oral appliances: an update for 2005. Sleep 2006;29:240-3.

23. Cartwright RD. Predicting response to the tongue retaining device for sleep apnea syndrome. Arch Otolaryngol 1985;111:385-9.

24. Kingshott RN, Jones DR, Taylor DR, Robertson CJ. The efficacy of a novel tongue-stabilising device on polysomnographic variables in sleep-disordered breathing: a pilot study. Sleep Breath 2002;6:59-66.

25. Lim J, Lasserson TJ, Fleetham J, Wright J (2006) Oral appliances for obstructive sleep apnoea. Cochrane Database Syst Rev (1):CD004435.

26. Marklund M (2006) Predictors of long-term orthodontic side effects from mandibular advancement devices in patients with snoring and obstructive sleep apnea. Am J Orthod Dentofacial Orthop 129:214-221.

27. Ferguson KA, Ono T, Lowe AA, al Majed S, Love LL, Fleetham JA (1997) A short-term controlled trial of an adjustable oral appliance for the treatment of mild to moderate obstructive sleep apnoea. Thorax 52:362-368.

28. Doff MH, Veldhuis SK, Hoekema A, Slater JJ, Wijkstra PJ, de Bont LG, Stegenga B (2011) Long-term oral appliance therapy in obstructive sleep apnea syndrome: a controlled study on temporomandibular side effects. Clin Oral Investig. doi:10.1007/s00784-011-0555-6. 
Egyptian

Orthodontic Journal

29. Ringqvist M, Walker-Engstrom ML, Tegelberg A, Ringqvist I (2003) Dental and skeletal changes after 4 years of obstructive sleep apnea treatment with a mandibular advancement device: a prospective, randomized study. Am J Orthod Dentofacial Orthop 124:53-60.

30. Tegelberg A, Wilhelmsson B, Walker-Engstrom ML, Ringqvist M, Andersson L, Krekmanov L, Ringqvist I (1999) Effects and adverse events of a dental appliance for treatment of obstructive sleep apnoea. Swed Dent J 23:117-126

31. Mehta A, Qian J, Petocz P, Darendeliler MA, Cistulli PA (2001). A randomized, controlled study of a mandibular advancement splint for obstructive sleep apnea. Am J Respir Crit CareMed 163:1457-1461.

32. Walker-Engstrom ML, Ringqvist I, Vestling O, Wilhelmsson B, Tegelberg A (2003) A prospective randomized study comparing two different degrees of mandibular advancement with a dental appliance in treatment of severe obstructive sleep apnea. Sleep Breath 7:119-130.

33. Rose EC, Staats R, Virchow C Jr, Jonas IE (2002) Occlusal and skeletal effects of an oral appliance in the treatment of obstructive sleep apnea. Chest 122:871-877.

34. Bloch KE, Iseli A, Zhang JN, Xie X, Kaplan V, Stoeckli PW, Russi EW (2000) A randomized, controlled crossover trial of two oral appliances for sleep apnea treatment. Am J Respir Crit Care Med 162:246-251.

35. Fritsch KM, Iseli A, Russi EW, Bloch KE (2001) Side effects of mandibular advancement devices for sleep apnea treatment. Am J Respir Crit Care Med 164:813-818.

36. Chen H, Lowe AA, de Almeida FR, Fleetham JA, Wang B (2008) Three-dimensional computer-assisted study model analysis of long-term oral-appliance wear. Part 2. Side effects of oral appliances in obstructive sleep apnea patients. Am J Orthod Dentofacial Orthop 134:408-417.

37. Marklund M, Franklin KA, Persson M (2001) Orthodontic sideeffects of mandibular advancement devices during treatment of snoring and sleep apnoea. Eur J Orthod 23:135-144. 
Egyptian

Orthodontic Journal

38. Almeida FR, Lowe AA, Otsuka R, Fastlicht S, Farbood M, Tsuiki S (2006) Long-term sequellae of oral appliance therapy in obstructive sleep apnea patients: part 2. Study-model analysis. Am J Orthod Dentofacial Orthop 129:205-213.

39. Ueda H, Almeida FR, Lowe AA, Ruse ND (2008) Changes in occlusal contact area during oral appliance therapy assessed on study models. Angle Orthod 78:866-872.

40. Hoekema A, Stegenga B, Wijkstra PJ, van der Hoeven JH, Meinesz AF, de Bont LG (2008) Obstructive sleep apnea therapy. J Dent Res 87:882-887.

41. AASM (1999) Sleep-related breathing disorders in adults: recommendations for syndrome definition and measurement techniques in clinical research. The report of an American Academy of Sleep Medicine Task Force. Sleep 22:667-689.

42. Hammond RJ, Gotsopoulos H, Shen G, Petocz P, Cistulli PA, Darendeliler MA (2007) A follow-up study of dental and skeletal changes associated with mandibular advancement splint use in obstructive sleep apnea. Am J Orthod Dentofacial Orthop 132:806-814.

43. Ghazal A, Jonas IE, Rose EC (2008) Dental side effects of mandibular advancement appliances-a 2-year follow-up. J Orofac Orthop 69:437-447.

44. Kato J, Isono S, Tanaka A, Watanabe T, Araki D, Tanzawa H, Nishino T (2000) Dose-dependent effects of mandibular advancement on pharyngeal mechanics and nocturnal oxygenation in patients with sleep-disordered breathing. Chest 117:1065-1072.

45. Aarab G, Lobbezoo F, Hamburger HL, Naeije M (2010) Effects of an oral appliance with different mandibular protrusion positions at a constant vertical dimension on obstructive sleep apnea. Clin Oral Investig 14:339-345.

46. Martinez-Gomis J, Willaert E, Nogues L, Pascual M, Somoza M, Monasterio C (2010) Five years of sleep apnea treatment with a mandibular advancement device. Side effects and technical complications. Angle Orthod 80:30-36. 
47. Tsuda H, Almeida FR, Tsuda T, Moritsuchi Y, Lowe AA (2010) Craniofacial changes after 2 years of nasal continuous positive airway pressure use in patients with obstructive sleep apnea. Chest 138:870-874.

48. Ueda H, Almeida FR, Chen H, Lowe AA (2009) Effect of 2 jaw exercises on occlusal function in patients with obstructive sleep apnea during oral appliance therapy: a randomized controlled trial. Am J Orthod Dentofacial Orthop 135(430):e1-e7, discussion 430-1. 